\title{
Challenges of COVID-19 for Fair Trade enterprises in attaining Sustainable Development Goals 2030
}

\author{
Jeetendra Dangol and Sunil Chitrakar
}

Jeetendra Dangol (ORCID 0000-0002-5863-8977) is Associate Professor at the Faculty of Management, Tribhuvan University (TU). He earned his PhD from TU where he has been teaching over two decades at graduate level and currently supervising $\mathrm{PhD}$ and Mhil research projects. He had served as Deputy Director of School of Management and currently heading Research Department at Public Youth Campus, TU. More than 30 articles on accounting and finance have been published in refereed journals. Prior to his academic journey he had worked in administration and finance for Centre for Rural Technology. Lately he has been engaged in teaching and research in social entrepreneurship.

Sunil Chitrakar (ORCID 0000-0002-4808-793X) is CEO of Mahaguthi Craft With Conscience and Visiting Faculty, Nepal Open University. He earned his PhD in Market and Entrepreneurship from Tribhuvan University. He was faculty member at School of Management, TU for five years and has been teaching over 20 years in affiliated colleges. He has been running a Fair Trade (FT) enterprise and actively engaged in national and international networks of FT. Currently he holds positions of Vice Chair at Fair Trade Group Nepal, Regional Representative at World Fair Trade Organization and Vice President at Federation of Handicraft Association of Nepal.

\begin{abstract}
This paper aims to explore challenges of COVID-19 in achieving sustainable development goal (SDG) I 'no poverty' by Fair Trade (FT) enterprises. The authors used focus group discussion (FGD) with seven members of World Fair Trade Organisation (WFTO) - Asia, from six different countries: Thailand, Bangladesh, Nepal, India, the Philippines, and Indonesia. Findings suggest that COVID-19 has posed bigger challenges to FT enterprises in achieving the SDGs since the pandemic has created challenges not only to the economic aspect but also to the health, education, safety and security of the communities. Due to COVID-19, the progress in attaining SDGs has slowed down, as global unemployment surged, global markets collapsed with a catastrophic economic downturn, which could eventually push more people to the pit of poverty. Stronger collaboration among the stakeholders is needed to achieve the SDGs.
\end{abstract}

Keywords: COVID-19; enterprises; Fair Trade; sustainable development goals

\section{Background of the Study}

According to the United Nations, poverty is the main global challenge, which had declined to 10 per cent in 2015 from 36 per cent in 1990, However, the World Bank has estimated that the COVID-19 could push 71 million people into extreme poverty in 2020 (World Bank, 2020). Likewise, UNDP estimates that human development will decline, that COVID-19 has increased the poverty rate for women and will widen the gap between men and women who live in poverty (UNDP, 2020). In 2018, workers living in extreme poverty reached 8 per cent, while in the present context 10 per cent of the world population (70o million people) is living in extreme poverty. Poverty reduction, creating jobs, protecting vulnerable communities and protecting workers have become 
more challenging due to the pandemic and bringing further challenges to attaining SDG 2030 goals (www. un.org/sustainabledevelopment/poverty/).

Mensah (2019) argued that the entire issue of sustainable development could be analysed via three distinct but interconnected pillars, namely the environment, economy and society. Sustainable development refers to growth and economic development, which must be socially acceptable and environmentally sound and reduce poverty (Rosen, 2019). This is related to the mindfulness of decision-makers and their responsibility towards the fulfillment of human needs. Fair Trade enterprises contribute to attaining SDGs (wfto.com) and to poverty reduction by creating jobs while adhering to environment and social standards (Chitrakar, 2015).

The SDGs are an ambitious set of 17 overarching global goals to combat poverty and achieve sustainable development by 2030. The first goal of SDG is 'End poverty in all its forms everywhere'. This goal is central to Fair Trade's mission. Elevating people from extreme poverty makes possible for them access to education, health care and basic needs, living without hunger and without social discrimination. Shi and colleagues (2019) argued that good governance, culture and life support systems are important factors in promoting sustainable development. Fair Trade enterprises contribute to improving overall well-being of marginalised producers by providing employment, paying fairly and providing good working conditions. They help achieve the first goal of SDG 2030, 'no poverty', through a Fair Trade premium or fair price, adopting Fair Trade standards and promoting programmes, partnership and advocacy (Fair Trade International, 2020).

In general, trade contributes to economic prosperity by utilising resources, generating employment and promoting people's livelihood; and it reduces poverty (Sthapit, 2020). However, the benefits of trade have not been equally received by poor and disadvantaged producers of the least developed countries and the situation is even worse in vulnerable communities (Gorkhali, 2019). Fair Trade (FT) has emerged as a sustainable business model that helps reduce poverty for millions of farmers and producers in least developed countries. Fair Trade contributes to sustainable development with better working conditions, providing inclusive business approaches which secure the rights of marginalised producers and farmers, and helps reduce environmental degradation by means of sustainable production and consumption practices. The overall vision of the Fair Trade movement is to create just and sustainable global trading systems that give opportunities for marginalised people, producers and farmers to access the market, improve their livelihoods and develop their full human potential (Chitrakar, 2015).

As the COVID-19 pandemic spares no one, FT enterprises are also hit hard. This paper addresses the impact of COVID-19 on the possible attainment of the SDGs 2030. Are these enterprises able to maintain their FT practices during the pandemic? Can they maintain their commitments backed by FT principles as they respond to the challenges of COVID-19? Do they have any programmes to cope with the problems of COVID-19? The main objective of the study is to explore the challenges of COVID-19 for Fair Trade enterprises and their responses in attaining SDG 2030 (Goal 1: no poverty).

The next section presents methodology of the study. The third section presents the results and discussions, and the last section provides the conclusions and implications.

\section{Research Methods}

An exploratory research design has been used in this study. It is based on primary data collected from a focus group discussion (FGD). The FGD was confined to seven respondents from six member countries of World Fair Trade Organisation (WFTO) - Asia: Thailand, Bangladesh, Nepal, India, Philippines and Indonesia. The major subject matter for the focus group discussion, schedule, expected outputs and other important information were communicated to participants prior to the discussion. The FGD was one and a half hours long held via Zoom, on Friday 9 October 2020.

The FGD focused on businesses' contribution in attaining SDG 2030 goals, mainly, the following issues:

- Fair Trade enterprise contributes to attaining Goal \#1 'No Poverty'

- Fair Trade contributes to improving present conditions of extreme poverty. 
Table 1 Participants' profile

\begin{tabular}{|c|c|c|c|c|}
\hline S.No. & Name of Organisation & Country & Position & Gender \\
\hline 1. & Mitra Bali Fair Trade & Indonesia & Trading Manager & Female \\
\hline 2. & Women's Education for Advancement \& Empowerment & Thailand & Executive Director & Female \\
\hline 3. & Y. Development Cooperation & Thailand & Executive Director & Female \\
\hline 4. & Prokrittee & Bangladesh & Executive Director & Male \\
\hline 5 . & Craft Resource Center & India & Executive Director & Male \\
\hline 6. & Community Crafts Association of the Philippines, Inc. & Philippines & Executive Director & Male \\
\hline 7. & Sana Hastakala & Nepal & Executive Director & Male \\
\hline
\end{tabular}

- Enterprises protect people and communities from falling into vulnerability.

- They promote equal opportunities for all in terms of economic livelihood.

- Extra measures have to be taken to protect people and communities from the climate crisis as poor people suffer most from this.

The discussion was recorded on Zoom with the permission of the participants, providing a guarantee of confidentiality of their views. In addition to recording the FGD, notes were also taken on the key points made by the participants. Both these notes and the audio recording were analysed and quotes extracted. These quotes are organised to synthesise the results as suggested by Berg (2001) for qualitative FGD-based research. A qualitative content analysis approach was used to analyse the contents of the discussion.

Table 1 provides background information about the participants. All the participants are from top management, with significant knowledge and experience in their respective businesses. Thus, their views should offer thoughtful insights on social innovation practices, sustainable development and capacity building.

\section{Results and Discussions}

\section{Businesses contribute to SDGs 2030}

When asked about whether businesses contribute to attaining SDGs 2030, most of the participants said that their businesses were doing very well in attaining these. Utilisation of resources and sustainable production practices create employment, ensuring sustainable income for producers that contributes to SDGs. One of the participants argued that:

Creating job opportunities for the people at the grassroots, specifically, in the rural and underdeveloped areas, strengthening supply chain of the small and medium enterprises (SMEs), increasing production capacity of the SMEs, sharing profits to the workers, maintaining consistency in business and making slow, but steady economic growths.

This indicates that the Fair Trade enterprises focus not just on their economic mission but also focus on promoting better livelihood opportunities for people by encouraging sustainable production and consumption practices. Similarly, they also viewed the significance of the SDGs as having profound impact on people, planet and profit. One of the participants argued that:

SDGs are the fundamental cornerstone to secure future economic and businesses prosperity. Therefore, it is not possible to have a strong, functioning businesses if they do not take climate action, reduce unemployment, strengthen gender equality, promote peaceful societies, and eradicate poverty.

One discussant said what they are doing to attain SDG:

Our organisation focuses on income-generation; we provide them various resources such as design input, logistics support, micro-finance, gender and health counselling and various other issues. We are at the same time friend, philosopher, and guide. 
The participants agree that Fair Trade enterprises provide opportunities for marginalised and poor producers and artisans. Abiding by the Fair-Trade principle \#1, they have a clear mission of reaching out to the poor and they have been using different instruments such as living wage, fair wage, financial support, business development support and capacity building to ensure long-term business and sustained income for the producers.

Most of the participants agreed that Fair Trade is a vital driver in contributing to SDGs. The present economic and social crisis has further highlighted the need for inclusive trade mechanisms that bring equity and development for most vulnerable communities and Fair Trade delivers that. One of participants stated:

Enterprises can contribute in accelerating SDG through: (i) correcting markets and government failures, ensuring that recovery programmes are geared towards rebuilding back fairer, (ii) aggressively promoting environmental sustainability by minimising policy tradeoffs, (iii) addressing poverty and inequality investing for the benefits of the poor and vulnerable, and (iv) harnessing social resources.

\section{FT enterprise contributes in attaining goal \#1 'no poverty'}

The SDG goal \# 1, 'No Poverty - End poverty in all its forms everywhere', directly corresponds to Fair Trade principle 1, 'Creating opportunity for economically disadvantaged producers'; principle 3, 'Fair trading practices' and principle 4, 'Fair payment'.

FT principle 1 ensures that FT enterprises have a clear mission to reduce poverty as it states:

Poverty reduction through trade forms a key part of the organization's aims. The organization supports marginalized small producers, whether these are independent family businesses, or grouped in associations or co-operatives. It seeks to enable them to move from income insecurity and poverty to economic self-sufficiency and ownership. The organization has a plan of action to carry this out. (WFTO, 2020)

All participants said that the FT enterprises are providing consistent income generation opportunities and timely payments, through marketing of their products in domestic and international markets. One discussant claimed that:

We have been providing marketing service and creating job for women and marginalised people for last 30 years. It has helped in creation of employment and income thus reducing poverty. Besides we provide various social and community development programmes and activities for them.

A discussant from Thailand said:

We contribute in poverty reduction within the Thai-Myanmar border through access to safe employment via the refugee artisanal crafts and community-based forestry management. We also use life learning approach by providing access to access quality education and development to refugee children and girls.

One of the participants noted that: 'To fight against poverty, we ensure that our producers receive fair prices for their products, long-term income, capacity-building and life-skills trainings, no discrimination, no slavery, and good working condition to ensure that their way out of poverty.' They target poor people, specifically, disadvantaged women in the underdeveloped areas, paying fair prices and fair wages, taking care of savings and retirement benefits. This helps to reduce poverty.

\section{Fair Trade contributes in improving present condition of extreme poverty}

FT principle \# 4 ensures that producers are paid fairly. FT enterprises are obliged to pay fair wages and prices in which the producers have right to negotiate. Moreover, the producers are paid a living wage that addresses the issue of decent living in the local context. The long-term trade relationship ensures that producers get enough and regular work, which ultimately brings sustained income above the extreme poverty income line of $\$ 1.25$ a day: 'We support marginalised artisans to access the market on regular basis; otherwise they would be vulnerable to middlemen exploitation who pay low wages and don't pay on time.'

Regarding wages rate, most of the participants expressed that they are paying fair wages and other benefits more than government's minimum wage rate. One of the participants said that: 
Fair Trade covers the cost of living of the artisans mostly in the rural area, where in general they normally earn less than government minimum wage, but we are paying wages that cover their living costs including their children's education expenses.

They believe that wages they are paying to small producers are able to meet their family needs. One of the participants from Thailand argued that Fair Trade brings more than monetary benefits:

Prior to COVID-19, refugee artisans and producers receive minimum wage of 9.1 USD per day (the border wage is 5 USD, and refugee wage was pegged at 2.5 US per day). If employment/daily income is one indicator for measuring poverty reduction, Fair Trade was able to contribute in improving the lives of the refugee artisans. However, for the women artisans, it goes beyond income. In past, the women refugee artisans were invisible, voiceless, marginalised and powerless, because they are women and refugees and did not have education, no income and no enabling space to improve themselves; they overly depended on their husbands for income. It has changed when they joined our Fair Trade. It's not just earning but also involvement and participation in decision-making, and all key relevant affairs of the business which lead to the transformative nature and advancement of women's status in their homes and their communities.

\section{Enterprises have achieved or contributed in eradicating poverty of most vulnerable}

We raised the issue of their enterprise's contribution to eradicating poverty of the most vulnerable communities/people. They are providing knowledge and skills, vocational training and providing sustainable income opportunities for those communities. They identify the most vulnerable families based on their income, gender and people with special needs. They prioritise women, low-income people or the disabled, based on personal contacts, referrals, community mapping and observations. Some of the criteria in selecting participants are local skill, know-how, local resources, environmental issues, entrepreneurial motivation and self-efficacy of women. These FT enterprises create jobs that ensure income, basic social security and decent working conditions. A discussant explained:

We target the poorest of the poor, specifically the widows, divorcees, separated/singled mothers in the rural setups where economic activities are almost absent for the women. Our organisational strategies guide us to reach the poorest of the poor in the underdeveloped areas and also needy women approach us for work.

One of the participants spoke of selecting small producers based on their Fair Trade compliance criteria: 'Many artisans groups approach us. The first thing we do is a Fair Trade audit. If we find they are working in a fair way, we work to develop their product lines and improve quality. We create samples and then approach to the buyers.' Similarly, a discussant explained that the process of identify the potential producer groups as:

We work with the organisations and programs in the Refugee Camps in near Myanmar and Thailand boarders for economic empowerment of women and rural community development. In collaboration with the women's groups, we identify the most disadvantaged and poorest women in those communities. Once selected, they go through adult learning education (including vocational skills) and they are developed as micro-enterprises and be part of our supply chain. The refugee women's cooperatives assist newly recruited artisans and producers (for handholding) until they are able to stand on their own.

The FT principle \# 1 ensures that these FT enterprises reach out to poor and disadvantaged communities. They should have a clear mission which is reflected in their strategies. Annually they monitor their progress, as one discussant mentioned: 'We set annual targets and conduct assessment and benchmark to monitor the progress we made.'

\section{Protect people and communities from falling into vulnerabilities}

Asked participants about how their social enterprises protect people and communities from falling into vulnerabilities, the majority of the participants said that they commit long-term business relationship that includes supports including sustainable orders, capacity development program, product design, soft loan and networking. Broadly, one of the participants pointed out that: 'When production gets disrupted and/or there are economic downturns, we use our savings to undertake hardship grant or special care projects to help the artisans and community people to overcome those vulnerable situations.' Additionally, one of the participants from Thailand expressed their experience very emotionally: 
Our interventions are geared to ensure that we are able to respond to the following humanitarian needs: (i) survival, (ii) protection, (iii) participation and (iv) access and to claim their rights to have education, health and other services. We are working with highly vulnerable individuals (refugees and people living in conflict/war-torn areas), we have to ensure that at the onset of every intervention, protection mechanisms are fully ingrained and understood by all participants and mainstreamed in our programming. We are also working within the local, provincial and national framework and systems to ensure that all our participants (not only women but children too!) have space to seek redress and justice when a violent act is committed against them.

Annually, we support more than 3,000 refugee pre-school children to have access to early childhood learning and development, including access to supplementary feeding and health services. Portions of our profit are funnelsed to support these initiatives. Thus, the employment opportunities offered under Fair Trade and our Community-Based Natural Resource Management Agri-venture initiatives are critical actions to ensure that women are earning safely and with dignity and they are financially independent to contribute to the needs of their family - food and child education.

We work with the UN Refugee Agency and a multi-stakeholder/inter-agency network in prevention, protection and persecution (seeking justice) intervention for refugees. Initiatives includes awareness raising, training and education (Gender Based Violence, Safeguarding, etc.) advocacy, to mention a few.

The participants shared different approaches and programmes to protect people and communities from falling into vulnerability.

\section{Promote equal opportunities for all in terms of economic livelihood}

The FT principle \#6: 'Commitment to Non-Discrimination, Gender Equity and Women's Economic Empowerment, and Freedom of Association' ensures equal opportunities for all and positive discrimination for vulnerable communities. This correlates well to SDG Goal 1 as FT promotes equal opportunities for all. As FT enterprises, one has to ensure there is no discrimination in any form or against anyone. The organisations must clearly demonstrate the policy that it promotes gender equity and other policy that promote inclusion. One of discussant said:'Through skill training and capacity building, we empower women which enable them to take care of their own livelihood needs of their communities.' Likewise:

Our handicraft artisans are 100 per cent women, however, our approach on household economy building realises the active involvement of men in strengthening their households. While women are leading in the production of handicrafts, their husbands are involved in the agri-ventures. This is particularly relevant in the context of the refugee confinement as all economic activities are confined inside the refugee camp.

These statements indicate the role of FT in empowering people while addressing the gender roles as well. Most of the participants' enterprises have prioritised women as their key target groups. One discussant opined:

We only work with women which helps them to be able to empower themselves economically and give them strengths to exercise their rights in the family and the community. We believe that, eventually, women will have equal opportunity if they can earn decent incomes.

The FT principles 4 and 8 contribute in promoting inclusion and developing capacities of producers that directly corresponds both to SDG Goal 1 and also SDG Goal 4 - 'Ensure inclusive and equitable quality education and promote lifelong learning opportunities for all'. FT plays a significant role in reducing gender gaps while empowering women in the economic and social sphere.

\section{Additional initiatives taken to protect people from the climate crisis}

Poor people suffer most from the climate crisis. Besides providing direct employment opportunities, most of the FT enterprises are engaged in climate actions such as tree planting, rainwater harvesting, raising awareness on the environment and climate change. They work with local initiatives, NGOs and communities for climate action. A discussant explained:

In couple of years, we have distributed thousands of plants to the artisans and communities surrounding our production centers. We believe that this would play a big role in protection of the poor people from the climate crisis. 
In addition, a respondent said that:

We are working in the middle of the jungles (on the Thai-Myanmar border), we have to ensure that we manage the natural resources wisely. Together with the Doi Wiangla Wildlife Sanctuary and refugee and Thai villages, we developed a Community Based Natural Resources Project (2012) that serves to provide interventions on: (i) Agro-forestry, conservation of denuded forests, (ii) Rehabilitation of secondary forests, and (iii) Wise utilisation of natural resources biodiversity. The local community produces charcoal from the waste. We also use natural dyes that is good for environment and human health. We promote sustainable farming practices utilising the wastes of livestock, and our farmers grow organic cotton.

It is shown that the Fair Trade enterprises are well versed in environmental protection and climate issues and taking climate action as part of their businesses.

\section{COVID-19 and its effect on enterprises}

All the participants outlined similar challenges when asked about the effects of COVID-19 on their business. Some of the key challenges expressed are the shutting down business, revenue plunging which resulted in severe financial problems and market collapse affecting demand. This has reduced livelihood opportunities for poor and vulnerable communities. One of the participants highlighted that:

COVID-19 has affected us in almost every way. For the last eight months our export sales declined over 65 per cent. COVID-19 has severely affected our ability to provide regular work to the refugee communities. While COVID-19 presented an opportunity to pivot and increase our domestic sales, however, the instability and economic downturn is making our business weaker. We have to use our reserves in order to continue our operations. With the looming crisis, it is a serious threat to our survival.

Due to COVID-19, the world has experienced severe economic crisis with the shutting down of the global economy and uncertainty still looms over future business. In this regard, a discussant said that:

We are experiencing economic crisis due to COVID-19. We have already experienced a loss of income (US $\$ 100,000)$ this year. This significantly affects our small artisans and their families. There is a fear that some of our artisans have to shut down their businesses completely; already ten out of 23 groups have shut down their businesses and lost income severely.

COVID-19 has had a profound economic impact; it is also affecting FT enterprises' capacity to support marginalised producers. The supply chain disruption has impacted future sales and businesses.

\section{Key challenges enterprises face during the COVID-19 pandemic}

Entire business operations have been halted, producers were not able to work and the market was closed, creating survival threats. Besides financial and operational problems, the staff and producers have also experienced emotional health issues. A discussant said that: 'We had to reduce our work time and the artisans had to work from home. There were also some challenges in arranging and carrying of the required raw materials for our productions.'

Businesses were forced to shut down and halt entire operations, resulting in the loss of present and future sales, with the liquidity crisis eventually weakening the firm's ability to support producers. The uncertain market and increasing pandemic put their sustainability at greater risk. This has slowed down SDG goal attainment as their priorities shifted from business growth to basic survival mode.

\section{COVID-19 and its effect on SDGs}

The COVID-19 pandemic will have brought an additional 88 million to 115 million people into extreme poverty at the end of 2020, with the total rising to as many as 150 million by 2021 (World Bank, 2020). The participants agree that the crisis will certainly create more challenges in meeting the global goals as poverty will rise across the globe and countries with small economies will suffer the most. Additionally, they believed that the progress of SDGs has slowed down due to COVID-19. One of the participants noted, on the basis of the Asia and Pacific SDG Progress Report 2020: 
The pandemic has widened inequality between men and women in terms of unpaid work, with women handling more child care and housework than ever before. Definitely, the global goals would be threatened as economies further shrink, public financing dries up and international cooperation wanes.

Most of participants stated that the COVID-19 pandemic has slowed down economic activities, and increased unemployment inequalities and injustice. Bello (2020) identified the three most serious areas as (i) the disruption of global and regional supply chains, (ii) distorted development and (iii) the problem of growth. The poor and vulnerable face tougher challenges as they lost their jobs as well as losing their future. Domestic violence, health problems, climate crisis and social injustice further create challenges for every country. The businesses will have added responsibility to help address these issues. The Fair Trade business model could be one of solutions by providing inclusive business. FT principles are multi-dimensional, trying to address many of these social, economic and ecological issues while doing business.

\section{Measures/strategies enterprise has taken or is planning to take to overcome challenges posed by COVID-19}

The pandemic has distressed everyone - physically, mentally, socially and economically. To reduce the distress caused by the crisis, most of the Fair Trade enterprises focused on minimising the social and economic problems of producers and staff. They prioritised health issues and distributed needed personal protection equipment (PPE), and medicines. They also set up flexible working options and work from home opportunities. Despite the difficulties, most of the workers resumed their work after the lockdown. FT enterprises are doing everything they can to reopen and look for opportunities to get back to business. One of the participants shared their strategy as: 'We closed our retail shop in the tourist area, and we make garage sale and will open the new shop in the city to grab the local consumers.'

Some of the participants explained that they are using their surplus to sustain the business; reducing the expenses as much they can; and they are thinking to look for online markets. Similarly, a discussant said that: 'We used some of our funds for undertaking some hardship grant and special care projects for the artisans and community; introduced/developed some new products and improved our online sales strategies'. One discussant said that:

We are using various modalities in ensuring that resources are made available (human, social, financial, physical, legal) as part of our response, recovery and re-enhancement interventions. Such interventions include, (i) working with various networks to raise Recovery Funds, (ii) engaging with governments (Thailand and Myanmar) to ensure our constituencies receive provisions of Social Protection, Social amelioration incentives (capital) and COVID-19 related health benefits, (iii) working with donors and investors for relief and recovery support, to mention a few, (iv) reconfiguration of our business model and mainstreaming crisis response strategies.

Despite the challenges most of FT enterprises are focusing on building back their businesses, seeking to strengthen their supply chain, pursuing market innovation through going online and extending networks for resources. They are sustaining current staff and producers. This approach correlates with the FT principle ensuring good business practices, promoting long-term relationships. This principle also ensures respect for each other and continuing trading relationships based on solidarity, trust and mutual respect that will contribute to the promotion and growth of Fair Trade (WFTO, 2020). This encourages FT enterprises to go the extra mile in exploring market opportunities, product innovation, technological upgradation and market development to remain in business. Strategic alliances in local context with civil society organisations, government and other fellow Fair Traders would give them an edge to lobby for helpful stimulus packages from government as well as develop strategically to mitigate the challenges of COVID-19.

\section{Conclusions and Implications}

No one has been spared from this COVID-19 pandemic. Economy, ecology, social and security aspects of every nation are all under threat; and smaller economies are most vulnerable, with massive unemployment, very little or no government support, climate depletion, increasing inequality gaps between genders, society and nations. 
Global crisis has always been an opportunity for innovation on business, economic, health and social fronts. Fair Trade was born after World War II to support war-torn communities in Europe, as trade was recognised as an alternative to aid; and aid for trade (AfT) was sooner emerged as an effective instrument globally to support the backward countries and communities (Sthapit, 2020). Hence, the role of businesses especially FT is ever growing, to cater for producers and communities who need jobs and livelihood options. FT enterprises need to innovate ways to promote sustainable livelihoods for vulnerable individuals and communities. The businesses have to remodel themselves to be more inclusive, crisis resilient and sustainable.

FT enterprises need to invest in innovation to build back their businesses and to build resilience. Managing costs and improving productivity should be the key issues while strengthening their supply chain. Technology would help achieve this. The consumer markets have also shifted during the pandemic; FT enterprises need to explore the new opportunities with product innovation and innovation in reaching out to those markets.

The policy-makers and government should encourage businesses to adopt FT practices as these contribute to attaining SDGs. FT enterprises collectively need to lobby for conducive policy frameworks to promote FT. Sustainable production and consumption initiatives should be promoted at the local, national and international levels.

\section{Acknowledgements}

We really appreciate the respondents who have voluntarily participated in this study. Special thanks to the anonymous reviewers for their critical reading of the manuscript and suggestions in relation to this paper. This study was sponsored by the UNESCO-UNITWIN, Center for International Development Cooperation, Handong Global University, Pohang, Republic of Korea.

\section{References}

Bello, W. (2020). COVID-19, distorted development, and degrowth. Retrieved from https://focusweb.org/covid-19-distorteddevelopment-and-degrowth/?fbclid=IwARopQyyRpo85HUDFXhW-WtXH201OSqL2XB1YncOl9_8bnZFEn883XYgyiiE

Berg, B.L. (2001). Qualitative research methods for the social sciences. Boston: Allyn \& Bacon.

Chitrakar, S. (2015). Fair Trade towards sustainable development goals 2030. Interaction on SDG 2030.Seminar, Fair Trade Group Nepal.

Fair Trade Foundation (2015, July). Delivering the sustainable development goals through trade - a five point agenda for policy coherence. Retrieved from www.FairTrade.org.uk

Fair Trade International (2020). SDG 1: No poverty. Retrieved from https://www.FairTrade.net/issue/sdg1

Gorkhali, S.P. (2019). Fair Trade and agenda 2030: Position paper of Fair Trade Group Nepal on sustainable development goals. Lalitpur: Fair Trade Group Nepal.

Mensah, J. (2019). Sustainable development: meaning, history, principles, pillars, and implications for human action: literature review. Cogent Social Sciences, 5(1), 1-21. https://doi.org/10.1080/23311886.2019.1653531

OECD (2004). Promoting entrepreneurship and innovative SMEs in a global economy: towards a more responsible and inclusive globalization. Promoting SMEs for Development. Istanbul: Organization for Economic Cooperation and Development.

Rosen, M.A. (2019). Advances in sustainable development research. European Journal of Sustainable Development Research, 3(2), 1-3. https://doi.org/10.29333/ejosdr/5730

Shi, L., Han, L., Yang, F. \& Gao, L (2019). The evolution of sustainable development theory: types, goals, and research prospects. Sustainability, 11, 1-16. https://doi:10.3390/su11247158

Shretha, S. (2020). Sustainable organizations to emerge as leaders during the COVID-19. International Journal of Entrepreneurship and Economic Issues, 4(1), 65-69.

Sthapit, A. (2020). International business: Environments and strategies (2nd Ed.). Kathmandu: Taleju Prakashan.

UN (n.d.) Sustainable development goals. Goal 1: end poverty in all its forms everywhere. Retrieved from https://www. un.org/sustainabledevelopment/poverty/

UNDP (2020). COVID-19 will widen poverty gap between women and men, new UN Women and UNDP data shows. Retrieved from https://www.undp.org/content/undp/en/home/news-centre/news/2020/_COVID-19_will_widen_ poverty_gap_between_women_and_men_.html 
WFTO (2020). Retrieved from https://wfto.com/our-fair-trade-system

World Bank (2020). Projected poverty impacts of COVID-19 (coronavirus). Retrieved from https://www.worldbank.org/en/ topic/poverty/brief/projected-poverty-impacts-of-COVID-19

World Economic Forum (2020). Why social entrepreneurs are critical to our response to and recovery from the COVID-19 crisis. Retrieved from https://www.weforum.org/agenda/2020/05/schwab-foundation-covid-response-alliance-socialentrepreneurs-coronavirus-recovery-response/

World Fair Trade Organization (WFTO) (2020). 10 principles of fair trade. Retrieved from https://wfto.com/our-fair-tradesystem\#10-principles-of-fair-trade

www.sustainabledevelopment.un.org (2015). Retrieved 31 October 2015 from sustainabledevelopment.un.org/?menu=100 www.un.org (2015). Retrieved 31 October 2015, from www.un.org/sustainabledevelopment/sumit/.

www.wfto.org. (n.d.). Retrieved 26 October 2015, from www.wfto.com/news/new-sustainable-development-goals-andfairtrade-ourpreliminary-analysis 